commendable. He is at his best describing expectancy theory, the acoustic and physical bases of pitch, consonance and tonality. He explains well the decisions that composers make given the constraints of style, form and tradition. The Music Instinct also contains representative, if abbreviated, coverage of seminal and recent research into music cognition.

How far are we today from understanding how music moves us? I suspect that we are close. We know that music activates regions throughout the brain, not just a single 'music centre'. As with vision, music is processed component by component, with specific neural circuits handling pitch, duration, loudness and timbre. Higher brain centres bring this information together, binding it into representations of contour, melody, rhythm, tempo, metre and, ultimately, phrases and whole compositions. Our memory for music is remarkable and melody recognition is robust. Listening to music activates reward and pleasure circuits in brain regions such as the nucleus accumbens, ventral tegmental area and amygdala, modulating production of the neurotransmitter dopamine.

We now need to learn how simple manipulations of acoustic parameters - such as pitch, intonation, timing, timbre and loudness — give rise to changes in our mental and emotional perception of a performance. For example, I can play all of the same notes that pianist Arthur Rubinstein played - even on the same piano he used to record Beethoven's Moonlight Sonata - but no one is going to mistake me for him. Critics call it his touch, but cognitive psychologists would reduce the difference to the interactions of the five dimensions above (or four in the case of the piano, in which intonation is fixed). How can so much emotional nuance come from these factors? Why do some people become master musicians, whereas others with equivalent training and practice do not? And what might be the genetic, personal, neural and social components of this difference? We still do not know much about why people like the music they do, or about aesthetic tastes in general.

The Music Instinct offers an expansive and high-level overview of a complex field. Ball is both an enthusiastic writer about music and a passionate listener engaged with its emotional meaning as much as with its intellectual puzzles - an Aristoxenus for his time.

Daniel J. Levitin is professor of psychology at

McGill University, Montreal, Quebec H3A 1B1,

Canada. He is author of This Is Your Brain On Music and The World in Six Songs.

e-mail:daniel.levitin@mcgill.ca

For more on science and music, see

www.nature.com/nature/focus/scienceandmusic.

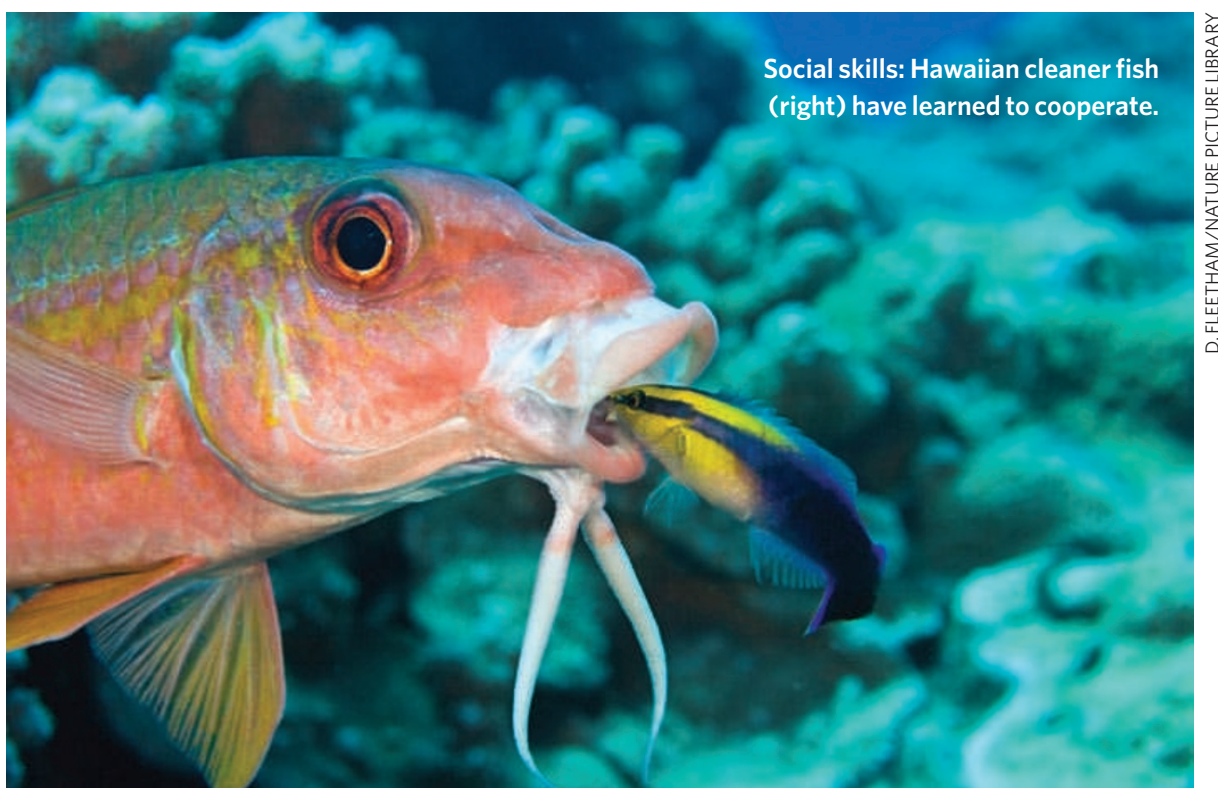

\title{
Once more into the animal mind
}

\section{Cognition, Evolution, and Behavior \\ by Sara J. Shettleworth \\ Oxford University Press: 2010 (2nd edn). \\ 720 pp. \$59.95, £40 \\ First edition published 1998}

The study of the mental lives of animals comparative cognition - is relatively new. Although Charles Darwin suggested in the nineteenth century that mental, as well as morphological, characteristics are subject to natural selection, the study of animal cognition did not take off until the 1970s, the offspring of a partnership between the fields of comparative psychology and animal behaviour. In the latest edition of Cognition, Evolution, and Behavior, experimental psychologist Sara Shettleworth provides a scholarly synthesis of current thinking in this fast-moving field.

The book is much more than a revision, reflecting the developments that have transformed the field in the decade since the first edition. Whereas topics such as spatial cognition - exploring how animals navigate and what they remember about their spatial environment - have seen incremental advances, others have exploded. The chapters on numerical and social cognition, covering how animals assess quantities and what they know about their social world, now extend beyond primates to species as diverse as dogs, goats, ravens, jays and cleaner fish. Shettleworth also discusses newly founded areas of study, including episodic-like memory, future planning and an animal's self-knowledge of what it knows (metacognition).

By taking a broad overview, Shettleworth resolves two critical conundrums within comparative cognition. The first is a tension between behaviouristic and mentalistic explanations of complex behaviour - namely whether the presence of a stimulus simply triggers a behavioural response or whether it engages a set of cognitive inferences. By adopting the critical stance of the behaviourist and acknowledging the theoretical concepts of the mentalist, Shettleworth integrates both perspectives in an informed way.

A second tension is whether comparative cognition should be viewed as a suite of adaptive specializations - from spatial skills to social smarts - or whether general-purpose processes, such as associative learning, have greater explanatory power. Here, too, she argues that both processes play a part in explaining how cognitive abilities arise. Shettleworth's analysis will catalyse the development of an overarching, integrated theory of comparative cognition.

Shettleworth's second edition provides considerable synthesis and a greater theoretical amalgamation with other disciplines, such as child development, cognitive science and neuroscience. The result is a detailed, nuanced and biologically informed view of how and why the cognitive capacities of various species can be the same yet different.

Nicky Clayton is professor of comparative cognition in the Department of Experimental Psychology, University of Cambridge, UK. e-mail:nsc22@hermes.cam.ac.uk 